\title{
Colaterais do arco aórtico no Gambá (Didelphis albiventris)
}

\author{
Collaterals of the aortic arch in opossun (Didelphis albiventris)
}

\author{
Sueli Hoff Reckziegel ${ }^{1}$ Tânia Lindemann ${ }^{2}$ \\ Paulete de Oliveira Vargas Culau ${ }^{3}$
}

\section{RESUMO}

No presente trabalho, foram utilizados 28 espécimes de Didelphis albiventris, 10 fêmeas e 18 machos. Após o preenchimento do sistema arterial com neoprene-látex corado, procedeu-se à dissecção para observação da disposição dos colaterais do arco aórtico. Em 11 casos $(39,29 \%)$, originou-se do tronco braquiocefálico primeiramente a artéria subclávia direita e posteriormente o tronco bicarotídeo o qual fornece as artérias carótidas comuns direita e esquerda. Em sete preparações (25\%), o tronco braquiocefálico trifurcou-se, originando as artérias subclávia direita, carótida comum direita e carótida comum esquerda. Em cinco observações $(17,86 \%)$, originou-se do tronco braquiocefálico primeiramente a artéria carótida comum esquerda e, logo após, a artéria subclávia direita e a artéria carótida comum direita. Em quatro achados (14,28\%), não houve a formação de um tronco braquiocefálico, primeiramente originou-se a artéria subclávia direita e, a seguir, um tronco bicarotideo. Em um caso (3,57\%), originouse do tronco braquiocefálico a artéria subclávia direita e a artéria carótida comum direita, sendo a origem da artéria carótida comum esquerda diretamente da aorta. Em todos os casos observados, a artéria subclávia esquerda originou-se diretamente da artéria aorta.

Palavras-chave: aorta torácica, anatomia, irrigação.

\section{ABSTRACT}

In this research 28 specimens of Didelphis albiventris, 10 females and 18 males were used. After performing the injections with neoprene-latex stained with specif pigment,

\begin{abstract}
the animals were dissected. The right subclavian artery was originated from the braquiocephalic trunk in 11 cases (39.29\%) and afterwards emerged the bicarotid trunk originating the right and left common carotid arteries. The braquiocephalic trunk divided into three branches, the right subclavian and the left and right common carotid arteries in 7 preparations (25\%). The left common carotid artery was originated from the braquiocephalic trunk in 5 cases $(17.86 \%)$, being followed by the right common carotid artery and the right subclavian artery. There was not a braquiocephalic trunk in 4 cases (14.28\%), so it was first originated at the right subclavian artery and after the bicarotid trunk. The right subclavian artery and the right common carotid artery were originated from the braquiocephalic trunk in one case $(3.57 \%)$, being the left common carotid artery originated directly from the aorta artery. The left subclavian artery originated directly from the aortic arch in all cases.
\end{abstract}

Key words: thoracic aorta, anatomy, irrigation.

\section{INTRODUÇÃO}

O objetivo deste trabalho é o estudo da disposição dos vasos colaterais do arco aórtico no gambá (Didelphis albiventris), visando determinar a ocorrência de variação nesta espécie. Em virtude do crescente interesse dos pesquisadores na utilização do marsupial como animal de laboratório e dada a escassez de informações disponíveis, principalmente

${ }^{1}$ Médico Veterinário, Mestre, Professor Adjunto de Anatomia Veterinária, ICBS, DCM, Universidade Federal do Rio Grande do Sul (UFRGS). Rua Mauro Mendes Totta, 92990-000 Sans Souci Eldorado do Sul. E-mail: preck@orion.ufrgs.br Autor para correspondência.

${ }^{2}$ Médico Veterinário, Mestre, Professor Assistente de Anatomia Veterinária, ICBS, DCM, UFRGS.

${ }^{3}$ Médico Veterinário, Doutor, Professor Adjunto de Anatomia Veterinária, ICBS, DCM, UFRGS. 
no concernente a sua anatomia, pretende-se com esta pesquisa, acrescentar novos dados relativos ao assunto.

SOUZA et al. (1982), estudando o comportamento dos colaterais do arco aórtico em 26 espécimes de Didelphis aurita, verificaram que, em 25 dos 26 casos $(96,15 \%)$, originaram-se do tronco braquiocefálico primeiramente a artéria subclávia direita e posteriormente o tronco bicarotídeo, o qual forneceu as artérias carótidas comuns direita e esquerda. Em apenas uma das 26 observações $(3,84 \%)$, o tronco braquicefálico emitiu primeiramente a artéria carótida comum esquerda e, em seguida, as artérias carótida comum direita e subclávia direita. Ressalte-se, ainda, que os autores citam que, em todos os casos, a artéria subclávia esquerda é o primeiro colateral do arco aórtico.

\section{MATERIAL EMÉTODOS}

No presente trabalho, foram utilizados 28 espécimes de Didelphis albiventris, 10 fêmeas e 18 machos, adultos, capturados em vários municípios do Estado do Rio Grande do Sul, com autorização do IBAMA, licenças $n^{\circ}$ 079/98 e 270/99. Os animais foram sedados com éter sulfúrico ${ }^{a}$, sendo imediatamente anestesiados com hidrato de cloral ${ }^{\mathrm{b}}$, na dose de $30 \mathrm{mg} /$ $\mathrm{kg}$, seguidos de $2500 \mathrm{UI}$ de heparina ${ }^{\mathrm{c}}$, via intraperitonial. Procedeu-se a seguir a abertura da caixa torácica e do saco pericárdico para posterior corte do ápice cardíaco, objetivando a canulação da artéria aorta através do ventrículo esquerdo. A seguir, foi feita injeção de solução salina para lavagem do sistema arterial, seguindo-se a injeção de látex ${ }^{\mathrm{d}}$, corado em vermelho com pigmento específico ${ }^{\mathrm{e}}$.

As peças permaneceram sob água corrente por uma hora para solidificação do material injetado. Após este tempo, as peças foram imersas em formol a $20 \%$ para fixação, no prazo mínimo de 170 horas. Procedeu-se, então, a dissecção para observação da disposição dos colaterais do arco aórtico. Com vistas à documentação, foram confeccionados desenhos esquemáticos de todas as preparações e fotografias de algumas.

\section{RESULTADOS}

Nas dissecções examinadas, verificou-se que, em 11 dos 28 casos (39,29\%), originaram-se do tronco braquiocefálico primeiramente a artéria subclávia direita e posteriormente o tronco bicarotídeo se dividindo em seguida nas artérias carótidas comuns direita e esquerda. Em cinco destas 11 amostras $(17,86 \%)$, a artéria subclávia direita surge imediatamente após a emergêngia do tronco braquiocefálico (figura 1B) e em seis dos 11 achados $(21,43 \%)$, a artéria subclávia direita surge alguns milímetros após (figura 1A e 2).

Em sete das 28 preparações ( $25 \%$ ), o tronco braquiocefálico trifurcou-se originando as artérias subclávia direita, carótida comum direita e carótida comum esquerda (Figura 1C). Em cinco das 28 observações $(17,86 \%)$, originou-se do tronco braquiocefálico primeiramente a artéria carótida comum esquerda e, logo após, a artéria subclávia direita emergiu em tronco com a artéria carótida comum direita (figura 1D).

Em quatro dos 28 achados (14,28\%), não houve a formação de um tronco braquiocefálico; primeiramente originou-se a artéria subclávia direita e a seguir um tronco bicarotídeo (Figura 1E e 3). Em um dos 28 casos (3,57\%), originou-se do tronco braquiocefálico a artéria subclávia direita e a artéria carótida comum direita, já a artéria carótida comum esquerda emergiu diretamente da aorta (Figura 1F). Em todos os casos observados, a artéria subclávia esquerda originou-se diretamente da artéria aorta.

\section{DISCUSSÃO}

Em relação aos ramos do tronco braquiocefálico, a artéria subclávia direita apareceu como primeiro ramo e com a formação do tronco bicarotídeo em 39,29\% dos casos. Para SOUZA et al. (1982), esse comportamento foi padrão, apresentandose em $96,15 \%$ dos casos. Em $17,86 \%$ dos casos o primeiro ramo do tronco braquiocefálico foi a artéria carótida comum esquerda surgindo logo após as artérias carótida comum direita e subclávia direita. Este arranjo foi o menos freqüente encontrado por SOUZA et al. (1982), ou seja, ocorreu em apenas 3,84\% dos casos. Em 25\% dos casos, o tronco braquiocefálico trifurcou-se originando as artérias subclávia direita, carótida comum direita e esquerda, o que não foi observado por aqueles autores.

A formação de um tronco bicarotídeo originando-se diretamente do arco aórtico ocorreu em $14,28 \%$ dos animais; tal arranjo também não foi encontrado nos espécimes estudados por SOUZA et al. (1982). Em 3,57\% dos achados ocorreu a presença do tronco braquiocefálico originando somente as artérias subclávia direita e carótida comum direita, sendo que a artéria carótida comum esquerda originouse diretamente do arco aórtico. SOUZA et al. (1982), não encontraram esta variação. Em 82,15\% dos achados, 


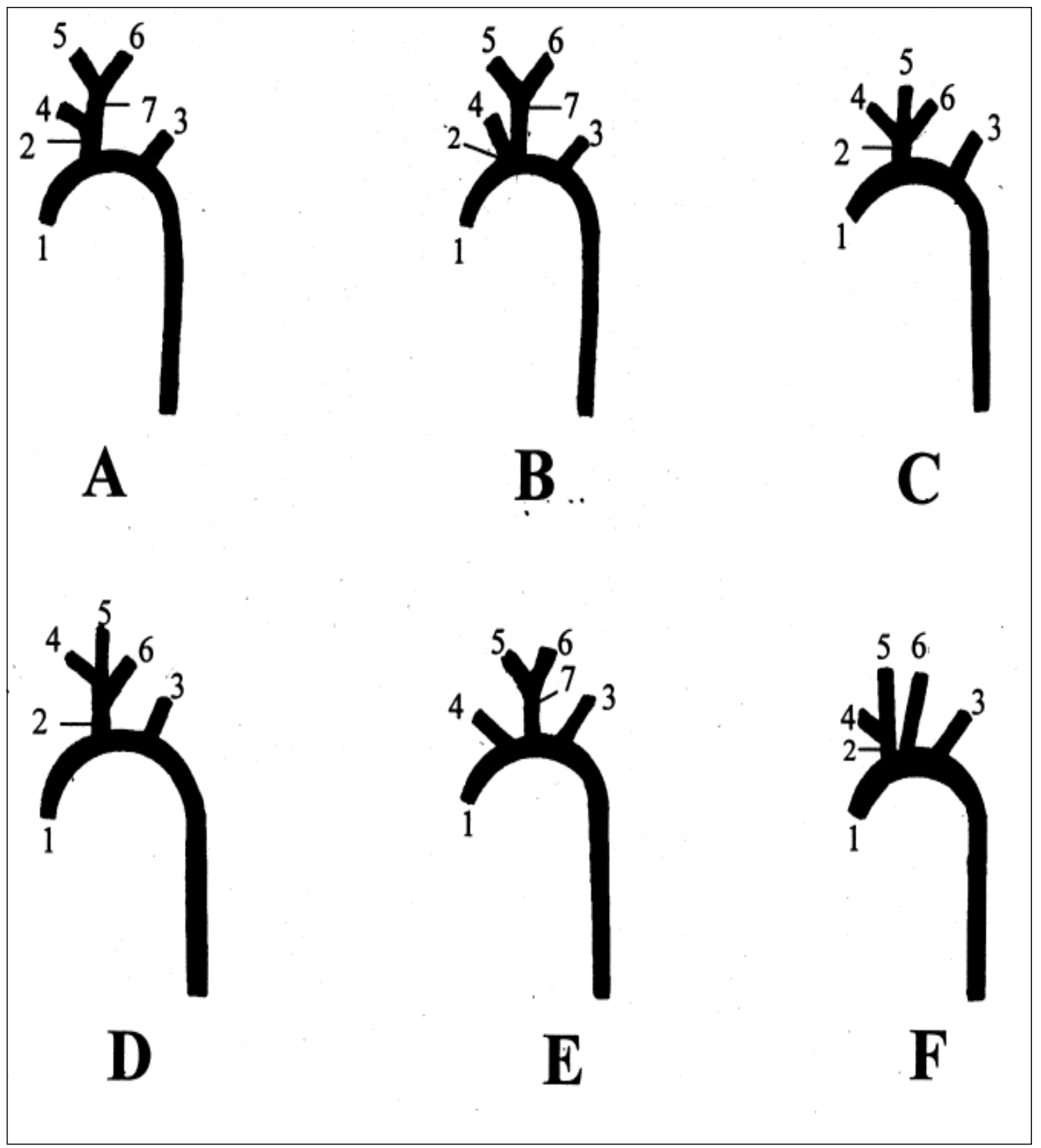

Figura 1 - Representação esquemática do arco aórtico e seus colaterais (A - F), no gambá (Didelphis albiventris). 1. arco aórtico, 2. tronco braquiocefálico, 3. a. subclávia esquerda, 4. a. subclávia direita, 5. a. carótida comum direita, 6. a. carótida comum esquerda, 7. tronco bicarotídeo.

a artéria subclávia esquerda surgiu como segundo ramo do arco aórtico e em $17,5 \%$ como o terceiro ramo, discordando de SOUZA et al. (1982) que encontraram esta artéria como o primeiro ramo do arco aórtico em $100 \%$ dos casos.

\section{CONCLUSÕES}

O arco aórtico do gambá (Didelphis albiventris) mostra variações quanto a seus ramos colaterais. Em 82,15\% dos casos, o tronco

Ciência Rural, v. 33, n. 3, mai-jun, 2003. 


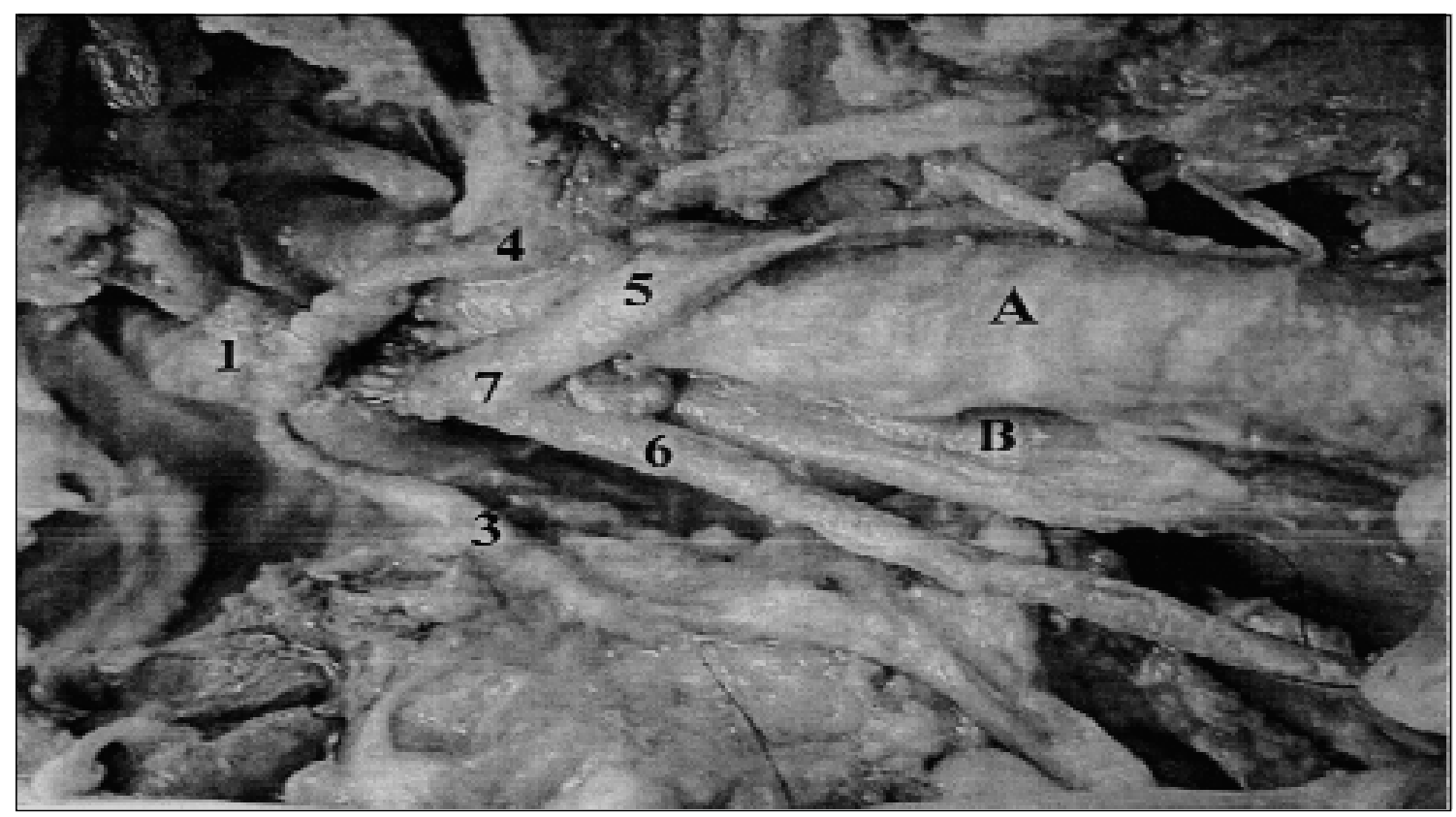

Figura 2 - Arco aórtico do gambá (Didelphis albiventris) e seus colaterais, mostrando a formação do tronco braquiocefálico: 1. arco aórtico, 2. tronco braquicefálico, 3. a. subclávia esquerda, 4. a. subclávia direita, 5. a. carótida comum direita, 6. a. carótida comum esquerda, 7. tronco bicarotídeo, A. traquéia, B. esôfago.

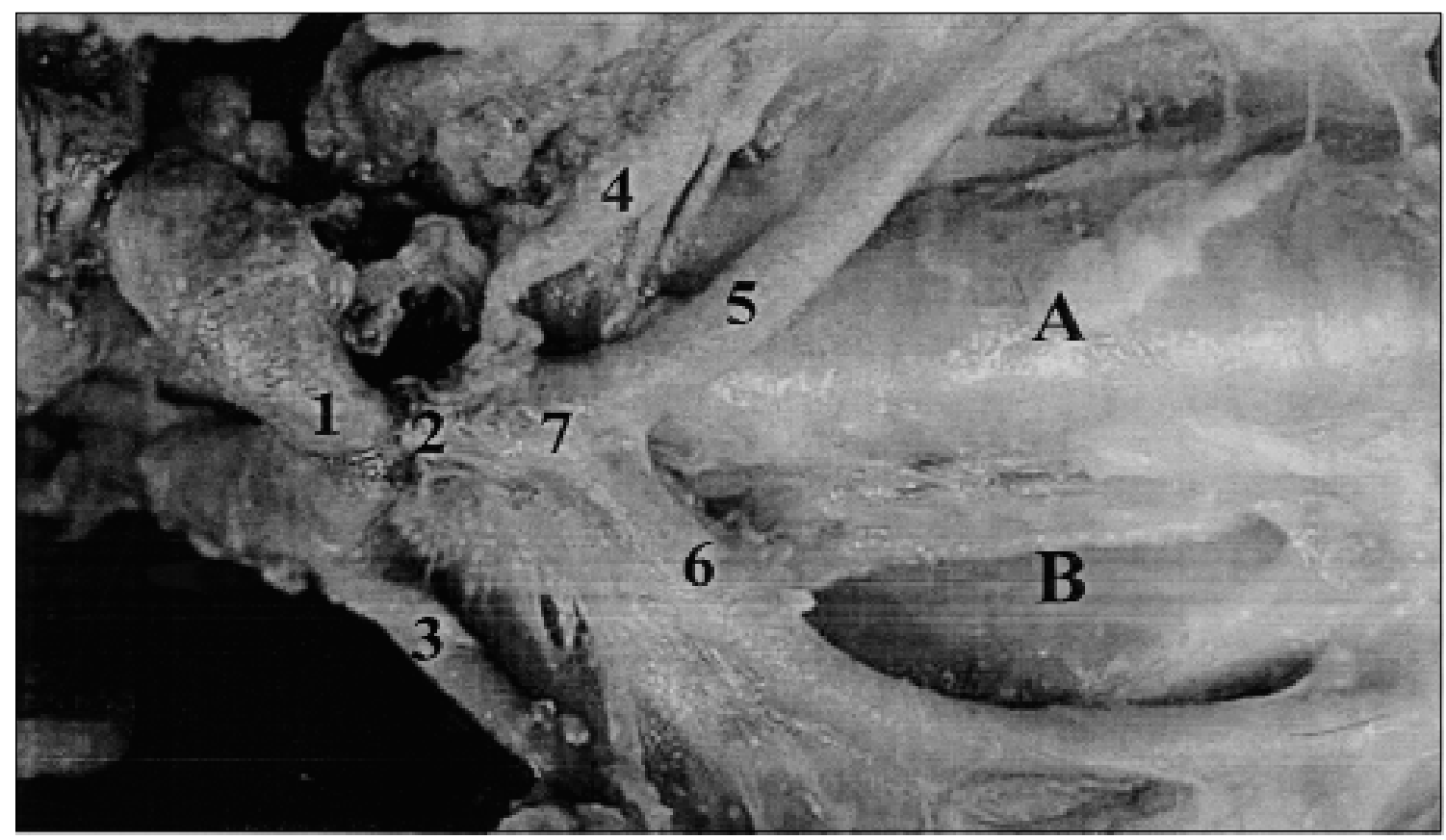

Figura 3 - Arco aórtico da gambá (Didelphis albiventris) e seus colaterais com a artéria subclávia direita originando-se diretamente do arco aórtico: 1. arco aórtico, 3. a. subclávia esquerda, 4 a. subclávia direita, 5. a. carótida comum direita, 6. a. carótida comum esquerda, 7. tronco bicarotídeo, A. traquéia, B. esôfago. 
braquiocefálico origina a artéria subclávia direita e as artérias carótidas comuns direita e esquerda, no entanto, em $14,28 \%$ dos casos, a artéria subclávia direita origina-se diretamente do arco aórtico seguida pela emergência do tronco bicarotídeo, não ocorrendo a formação do tronco braquiocefálico. Em 3,57\%dos casos o tronco braquiocefálico origina apenas as artérias subclávia direita e carótida comum direita, com a artéria carótida comum esquerda originando-se diretamente do arco aórtico. A emergência da artéria subclávia esquerda é sempre diretamente do arco aórtico.

\section{FONTES DE AQUISIÇÃO}

a - Technion Indústrias Químicas Exportadora Ltda

b - E. Merck AG

c- Liquemine - Roche

d - Artecola

e - Suvinil corante - Basf S.A.

\section{REFERÊNCIAS BIBLIOGRÁFICAS}

SOUZA, W.M.; MIGLINO, M.A.; ALBUQUERQUE, J.F.G. Contribuição ao estudo dos colaterais calibrosos do arco aórtico no gambá (Didelphis aurita). Arq Biol Tecnol, v.25, n.2, p.207-209, 1982.

Ciência Rural, v. 33, n. 3, mai-jun, 2003. 